\title{
Hypoxia during VV ECMO
}

\author{
Pranay Oza ${ }^{1}$ \\ ${ }^{1}$ Riddhivinayak Critical Care and Cardiac Centre, Mumbai, Maharashtra, \\ India
}

J Card Crit Care TSS 2017;1:57-59

Venovenous extracorporeal membrane oxygenation (VV ECMO) is the preferred mode for any kind of acute respiratory failure. The desired $\mathrm{PO}_{2}$ is $>50$ and $\mathrm{SPO}_{2}>88 \%$ but the acceptable values can be $\mathrm{PO}_{2}>45$ and $\mathrm{SPO}_{2}>80 \%$. In case if we are accepting lower $\mathrm{PO}_{2}$, we have to keep a higher hematocrit and meticulously monitor neurological status, lactates, and urine output to maintain oxygen delivery. Saturation during ECMO run depends on ECMO circulation, native circulation, and ratio of ECMO flow to cardiac output (- Table 1). Whenever the effective ECMO circulation decreases, saturation decreases. So, decrease in ECMO flow, ECMO FiO ${ }_{2}$, failing membrane oxygenator, and increase in recirculation will lead to hypoxia. Similarly, anything that decreases the contribution from native circulation will also lead to hypoxia. So, decrease in ventilator settings and worsening lung status lead to hypoxia. Anything that increases metabolism, such as fever and restlessness, will also cause hypoxia due to increased consumption.

Table 1 Causes of hypoxia during ECMO

\begin{tabular}{|c|}
\hline Technical problem \\
\hline Ventilator related \\
\hline Ventilator malfunctioning \\
\hline ET tube blockage \\
\hline $\begin{array}{c}\text { ECMO related } \\
\text { Decreased ECMO flow or }\end{array}$ \\
\hline FiO $_{2}$ \\
\hline Oxygenator failure $^{\text {Increase recirculation }}$ \\
\hline Lung condition worsening \\
\hline Parenchymal worsening \\
\hline Pneumothorax \\
\hline Increased ratio of ECMO flow/cardiac output \\
\hline Increased cardiac output \\
\hline
\end{tabular}

Abbreviation: ECMO, extracorporeal membrane oxygenation.
Address for correspondence Pranay Oza, BHMS, Riddhivinayak Critical Care and Cardiac Centre, S.V. Road, Malad (W), Mumbai 4000064, Maharashtra, India (e-mail: drpranay.oza@gmail.com).

Recirculation is defined as the flow of oxygenated blood from the returning cannula to the draining cannula without entering systemic circulation. It decreases the efficacy of VV support. Around $30 \%$ of recirculation is average. ${ }^{1}$ The factors on which the recirculation depends are pump flow ( - Fig. 1), catheter position, cardiac output, and RA size or intravascular volume. The recirculation can be calculated with the help of following equation: ${ }^{2}$

$$
\mathrm{R}=\frac{\mathrm{S} \text { pre } \mathrm{Ox}-\mathrm{SvO2}}{\mathrm{S} \text { post } \mathrm{Ox}-\mathrm{SvO2}}
$$

Management of hypoxia will depend on treating the underlying cause (-Fig. 2). The usual strategy is to increase oxygen transfer by increasing ECMO flow, ECMO $\mathrm{FiO}_{2}$, or by increasing hematocrit and thereby improving oxygen delivery. Many a times hypoxia is secondary to increased metabolic rate and just controlling that (controlling fever, giving sedation) will improve saturation. Recirculation can be managed by adjusting the flow; sometimes a higher flow is the cause of recirculation and just by decreasing flow we can get better saturation. ${ }^{3}$ Too close placement of tip of drainage and return cannula may lead to recirculation and just repositioning of

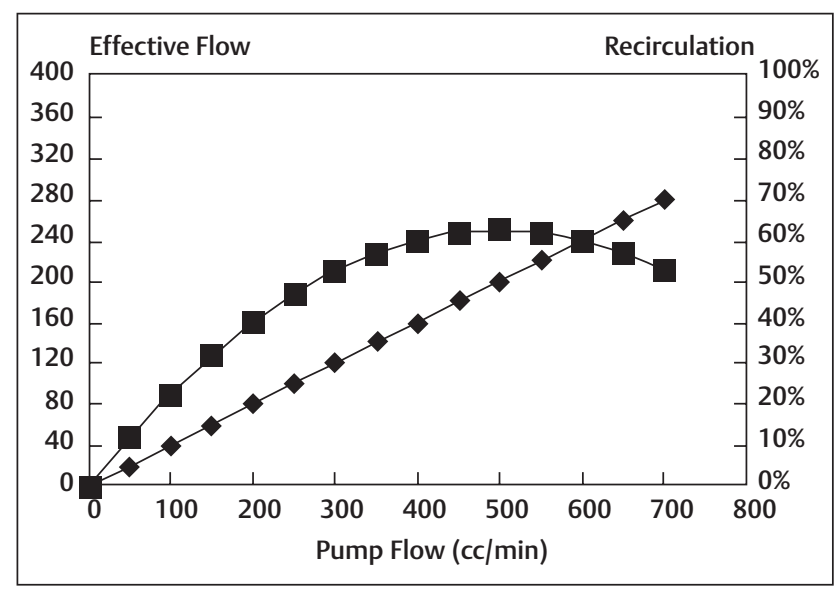

Fig. 1 Recirculation: defining the curve.
DOI https://doi.org/ 10.1055/s-0038-1626681. ISSN 2457-0206.
Copyright $\odot 2017$ Official Publication of The Simulation Society (TSS), accredited by International Society of Cardiovascular Ultrasound (ISCU)
License terms

(우 (1) $\Theta \circledast$ 


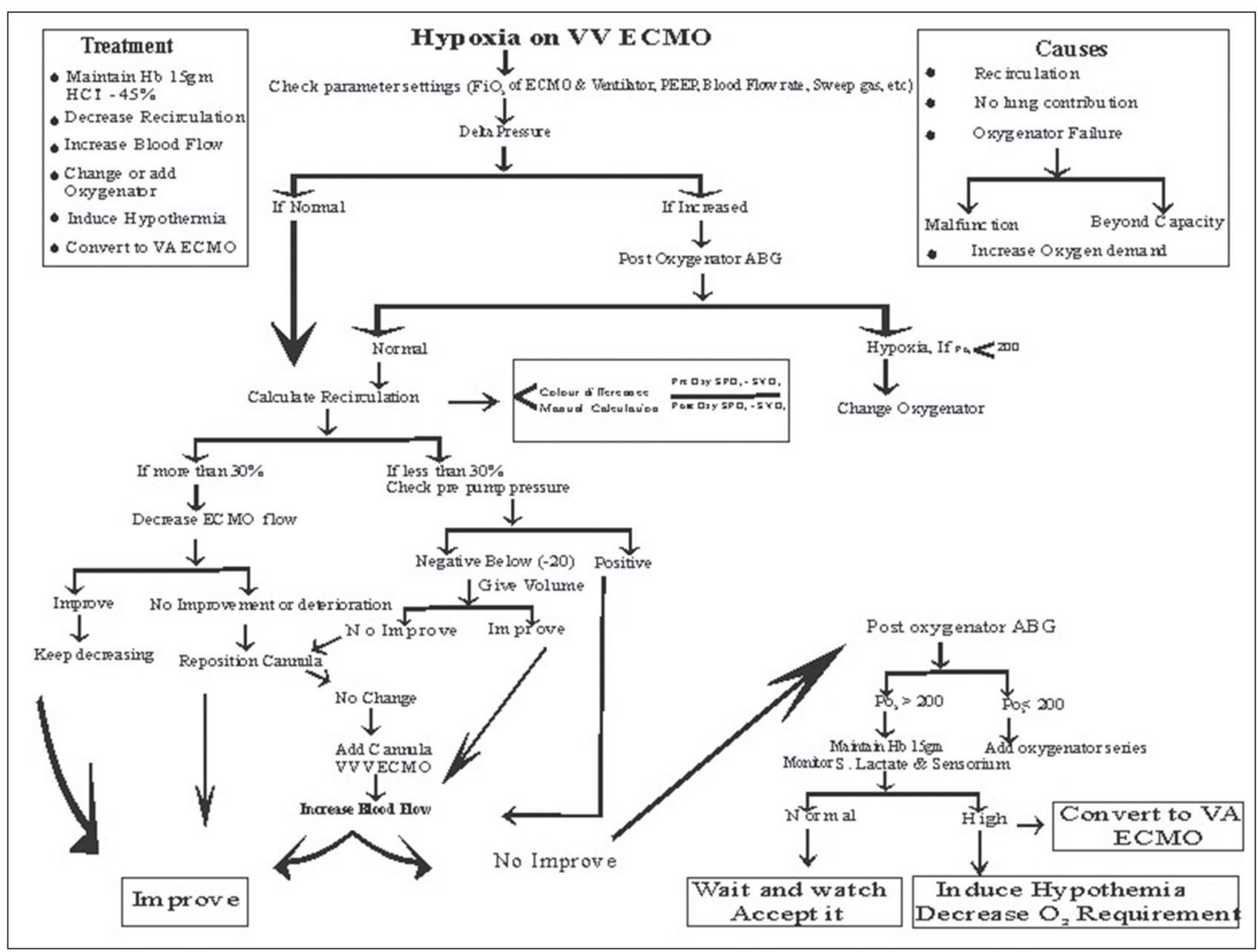

Fig. 2 Approach to hypoxia during VV ECMO. VV ECMO, venovenous extracorporeal membrane oxygenation.

cannula can improve saturation. ${ }^{4}$ If the recirculation persists, the last solution is to put additional cannula for drainage and switch to VVV ECMO.

In spite of all the above measures if the patient remains hypoxic and lactates are rising, then the last resource is to induce hypothermia and ultimately switch to VA or VAV ECMO (-Table 2).

\section{Conclusion}

Management of hypoxia during VV ECMO requires attentive monitoring and expedited, algorithmic monitoring. ${ }^{5}$ It is a balancing act that requires intense vigilance and expertise.

\section{Acknowledgments}

We sincerely thank the entire mobile ECMO team of the Riddhivinayak Critical Care and Cardiac center for their dedication and hard work.
Table 2 Management of hypoxia during VV ECMO

\begin{tabular}{|l|}
\hline Maximizing gas transfer \\
\hline Increase blood flow through the ECMO \\
\hline Increasing $\mathrm{FiO}_{2}$ of ECMO \\
\hline Increasing hematocrit \\
\hline Minimizing oxygen utilization \\
\hline Decreasing metabolic rate: control fever, sedation, etc \\
\hline Hypothermia \\
\hline Decreasing recirculation in VV ECMO \\
\hline Define the curve \\
\hline Cannula reposition \\
\hline $\begin{array}{c}\text { Add cannula: for drainage, cannula can be added in IVC, } \\
\text { SVC, and preferred cephalad cannula }\end{array}$ \\
\hline Conversion to VA or VAV ECMO \\
\hline
\end{tabular}

Abbreviations: ECMO, extracorporeal membrane oxygenation; IVC, inferior vena cava; SVC, superior vena cava; VAV, veno-arterial-venous, $\mathrm{VV}$, venovenous. 


\section{References}

1 Goyal V, Oza P. Venovenous ECMO. ECMO Theoretical Manual 2012;2(1):77-89

2 Goyal V, Oza P. ECMO Volume I, Practical Manual. Vol. 1

3 Heard M, Davis J, Fortenberry J. Principle and practice of venovenous and venoarterial ECMO. ECMO Specialist training manual. Billie Lou Short, Lisa Williams MHA, BSN, RNC-NIC; 2010:59-76
4 Bartlett R. Management of ECLS in adult respiratory failure. In: Van Meurs K, Lally K, Peek G, Zwischenberger J, eds. ECMO Extracorporeal Cardiopulmonary Support in Critical Care, Red Book. 3rd ed. ELSO, Ann Arbor;2005:403-416

5 Goyal V, Oza P. Algorithm. ECMO Theoretical Mannual 2012;2(1):248-250 